\title{
Oportunidades de desarrollo para la publicidad en la televisión interactiva: diseño y tipos de incentivo en los formatos de DAL
}

\author{
Laura AYMERICH-FRANCH $^{1}$ \\ GRISS, Grupo de Investigación en Imagen, Sonido y Síntesis \\ Universitat Autònoma de Barcelona
}

\begin{abstract}
RESUMEN:
Las posibilidades interactivas en la televisión dan cabida a formatos publicitarios aún por explotar. Sin embargo, es importante que antes de implementar este tipo de publicidad en nuestro mercado se repiensen los formatos existentes y se efectúen las innovaciones necesarias para que supongan un avance verdadero dentro de la publicidad, tanto en relación al propio medio televisivo como a otros medios. En este sentido, el presente trabajo contribuye a conocer mejor la respuesta de los usuarios a nivel de diseño y de tipos de incentivo ofrecidos en las aplicaciones de este tipo. Para ello, se diseñó un estudio experimental en el que 111 sujetos interactuaron con un Dedicated Advertiser Location (DAL) o un Mini-DAL, dos de los principales formatos existentes en el mercado, y valoraron el proceso de interacción y la posibilidad de solicitar más información del producto o una muestra gratuita a través de la aplicación. Los resultados del estudio muestran que la experiencia de interactuar con una aplicación de este tipo es en general positiva y por lo tanto su implantación en el mercado podría recibir una buena acogida. Por otro lado, la posibilidad de solicitar más información se percibe significativamente más útil y fiable en comparación a pedir una muestra gratuita. Por último, se discuten las posibilidades que el mercado publicitario debería explorar en la nueva televisión digital interactiva teniendo en cuenta la evolución del panorama mediático actual.
\end{abstract}

PALABRAS CLAVE: Publicidad interactiva; televisión interactiva; interactividad; usabilidad; incentivo.

TITLE: Opportunities for interactive TV advertising development: design and incentive types in DAL formats

\begin{abstract}
:
Interactive possibilities in television facilitate the emergence of advertising formats that have not been explored yet. However, it is important to rethink the existing formats before implementing this type of advertising in our market. Innovations over these formats are needed in order to obtain a real advance in advertising, both in relation to television medium itself and in relation to other media. This work contributes to a better understanding of user responses in terms of design and types of incentives offered in such applications. To do this, an experimental study was designed in which 111 subjects interacted with a Dedicated Advertiser Location (DAL) or a Mini-DAL, two major formats on the market, and assessed the process of interaction and the possibility to request further product information or a free sample through the application. The results show that the experience of interacting with an application of this type is generally positive and therefore its presence in the market could be well received. On the other hand, the possibility of requesting further information is perceived significantly more useful and reliable compared to requesting a
\end{abstract}

${ }^{1}$ Investigación realizada dentro del GRISS, Grupo de Investigación en Imagen, Sonido y Síntesis (2009SGR1013) y del proyecto CSO2009-12822 del Plan Nacional I+D+I. 
free sample. Finally, the possibilities that the advertising market should explore in the new digital interactive television are discussed considering the evolution of the current media landscape.

KEYWORDS: Interactive advertising; interactive television; interactivity; usability; incentive.

\section{Introducción}

La publicidad interactiva para televisión se encuentra en una fase de standby en nuestro país. El estándar MHP no tuvo la acogida esperada en el mercado nacional y privó sustancialmente el desarrollo de aplicaciones interactivas para televisión. No obstante, la inminente convergencia entre televisión digital e Internet aportará previsiblemente avances importantes a nivel de interactividad al medio televisivo, facilitando también la proliferación de formatos publicitarios que se nutran de la interactividad.

Estudios previos subrayan que los formatos publicitarios interactivos para televisión tienen un impacto positivo sobre la actitud de los usuarios hacia la publicidad y la marca anunciante e incrementan la intención de compra, en comparación a los formatos tradicionales (Bellman et al. 2009; Reading et al. 2006).

Además, se ha demostrado que características como la personalización, la interactividad o el hecho de que el consumo de estas aplicaciones se efectúe solamente con el consentimiento del consumidor ayudan a que los telespectadores acepten mejor la publicidad, se reduzca la reticencia a la exposición, aumente la implicación de los consumidores y contribuya a una mayor rentabilidad de la inversión de los anunciantes (Truong et al. 2010).

El presente estudio pretende avanzar en el conocimiento que se tiene de la respuesta de los usuarios ante este tipo de aplicaciones a fin de conocer sus posibilidades de implementación en el mercado.

\section{El panorama actual de la publicidad interactiva en televisión}

No existe una tipología unificada de los formatos de publicidad interactiva en televisión. No obstante, es posible recopilar los principales formatos de publicidad interactiva existentes en el mercado y ofrecer una breve descripción de cada uno, como hace el presente artículo. Para ello, se parte principalmente de los mercados británico y estadounidense, dos de los países con más presencia de publicidad interactiva en TV. Así, los principales formatos de publicidad interactiva que encontramos actualmente en la televisión digital son (Aymerich-Franch, 2007, 2008; Channel4 on line; IAB, 2010; Sky Media Ireland on line; Sky Media UK on line; Think Box on line):

- DAL y Mini-DAL: El DAL es el formato más complejo de todos los existentes. Se trata de espacios exclusivamente publicitarios que obligan a abandonar la emisión televisiva durante su consulta. La estética de estas aplicaciones es similar a la de un menú de DVD. Incluye un menú de navegación desde el cual se 
puede acceder a distintos espacios que pueden contener texto, imágenes, sonido, vídeo y animaciones. La navegación por este espacio es de tipo no-lineal. Los DAL suelen contener información sobre el producto o servicio y la posibilidad de contactar el anunciante para recibir más información, pedir catálogos, participar a sorteos y concursos, pedir muestras gratuitas o probar productos. Algunas veces incorporan pequeños juegos o algún tipo de material que supone un valor añadido para el usuario. El Mini-DAL es la versión reducida del DAL. No dispone de menú de navegación, el número de pantallas que puede consultar el telespectador es mucho menor y la navegación es de tipo no lineal. El Mini-DAL no permite incorporar material de vídeo, solamente texto, gráficos e imágenes.

- Microsite: A diferencia del DAL y el Mini-DAL, el Microsite permite mantener el contacto con la emisión televisiva mientras dura la consulta, que habitualmente queda reducida a un cuarto de pantalla. El usuario puede navegar por la aplicación interactiva que puede contener texto, gráficos, imágenes y animaciones. De la misma manera que los formatos anteriores, también puede incorporar un formulario de contacto con el anunciante. El término Microsite es de los más polisémicos dentro del grupo de formatos publicitarios interactivos y no siempre define el tipo de aplicación aquí descrita.

- Impulse Response: Es de los formatos más sencillos existentes. Un recuadro de texto aparece superpuesto generalmente en la parte inferior de la pantalla. El usuario puede seguir con el visionado televisivo normal mientras rellena un formulario que permite al anunciante contactar con él. Los usos más frecuentes son pedir más información, catálogos o muestras sobre el producto o servicio anunciado.

- Anuncio extendido bajo demanda: Contenido audiovisual relacionado con el producto o servicio anunciado. El telespectador accede al contenido bajo petición pero no interactúa con éste, dado que se trata solamente de material audiovisual. Generalmente contiene versiones extendidas del anuncio, $m a-$ king of, mini-sodios (episodios de duración muy reducida de, por ejemplo, una ficción o un pequeño reportaje) o tráileres de películas.

Además, la posibilidad de consumir televisión a través de nuevos soportes y la aparición de nuevos servicios como por ejemplo la televisión a la carta han propiciado que formatos publicitarios propios de otros medios (especialmente de Internet) como banners o spots pre-roll, mid-roll y post-roll pasen a incorporarse a las posibilidades publicitarias de la televisión interactiva cuando ésta se consume en Internet.

Por otro lado, el acceso a las aplicaciones publicitarias interactivas se realiza mayoritariamente a partir de iconos de interacción o triggers superpuestos al contenido audiovisual, banners incorporados en otros servicios interactivos o en pantallas de pausa o borrar de los personal video recorders (PVR), o dentro de una lista de programación, por ejemplo, en los listados de programas de un grabador de vídeo digital o en las guías electrónicas de programación (IAB, 2010). La navegación por las aplicaciones se efectúa mediante el mando a distancia interactivo. 
Finalmente, los principales soportes de las aplicaciones interactivas son los spots televisivos, los patrocinios interactivos a programas, las guías electrónicas de programación, los walled garden (grupos de servicios interactivos de distintas compañías provistos por el operador), el vídeo bajo demanda (VOD), el PVR y otras aplicaciones interactivas, sobretodo, páginas de juegos.

El presente estudio eligió las aplicaciones de DAL y Mini-DAL con la finalidad de analizar las posibilidades de explotación de estos formatos en el mercado español. Se eligieron estas aplicaciones por ser las más avanzadas en cuanto a posibilidades de consulta de información y navegación ofrecidas al usuario. También, se exploraron aspectos relacionados con la usabilidad de la aplicación en el proceso de navegación. En este sentido, se plantearon las siguientes preguntas de investigación:
$\mathrm{PI}_{1}$ : ¿Las aplicaciones de DAL y Mini-DAL resultan usables a los usuarios en el proceso de navegación por la aplicación?
$\mathrm{PI}_{2}$ : ¿Existen diferencias significativas entre DAL y Mini-DAL en la percep- ción de usabilidad de las aplicaciones durante el proceso de navegación?

\section{El incentivo en las aplicaciones de publicidad interactiva en televisión}

Los telespectadores distinguen un spot interactivo de uno convencional en un bloc publicitario por el icono de interacción. Se trata de pequeños símbolos o iconos situados en una esquina de la pantalla que invitan al usuario a pulsar el botón interactivo del mando a distancia (habitualmente el botón rojo o verde). Eso permite acceder a la aplicación interactiva. Ofrecer un incentivo al telespectador para que pulse el botón y proporcione sus datos voluntariamente al anunciante es un recurso comúnmente utilizado en esta etapa del proceso. Por ejemplo, el icono de interacción puede contener frases del tipo "si quieres ver el tráiler, pulsa el botón rojo" o "si quieres probar el producto gratuitamente, pulsa el botón interactivo", etc.

Entre los incentivos más comunes se encuentran el de recibir catálogos o más información del producto, participar a sorteos, recibir ofertas, descuentos y promociones, recibir muestras gratuitas, merchandising o regalos sorpresa o hacer un test del producto (sobre todo en coches) (Baird, 2001). El usuario contacta con el anunciante mediante el mecanismo de respuesta provisto en la aplicación, que envía los datos de contacto.

El estudio presentado analizó dos de los incentivos más habituales: el ofrecimiento de envío de más información sobre el producto y el envío de una muestra gratuita. Se planteó la siguiente cuestión:

$\mathrm{PI}_{3}$ ¿Cómo valoran los usuarios la posibilidad de solicitar más información del producto a través del mecanismo de respuesta?

$\mathrm{PI}_{4} \quad$ ¿Cómo valoran los usuarios la posibilidad de solicitar una muestra gratuita del producto a través del mecanismo de respuesta? 
$\mathrm{PI}_{5} \quad ¿$ Cuál de los incentivos propuestos (muestra gratuita $v s$ más información) genera mejor respuesta entre los usuarios?

\section{Procedimiento y método}

Ciento-once estudiantes universitarios ( 75 mujeres y 36 hombres entre 17 y 28 años, $x=20$ ) participaron en el estudio. Se diseñaron cuatro aplicaciones de publicidad interactiva para televisión: un DAL y un Mini-DAL que ofrecían la posibilidad o bien de pedir una muestra gratuita del producto anunciado o bien de pedir más información sobre el producto. Las aplicaciones eran accesibles a partir de un spot interactivo. Todas las aplicaciones ofrecían información sobre el mismo producto de fideos instantáneos.

Los participantes visionaban individualmente un pequeño programa, una tira de anuncios y luego el anuncio interactivo, que contenía un icono de interacción. Al pulsar el botón interactivo del mando a distancia tenían la posibilidad de navegar por la aplicación y rellenar el formulario para solicitar o bien la muestra o bien más información. Las aplicaciones de DAL contenían más información sobre el producto, las variedades existentes y el mecanismo de respuesta. El mini-DAL contenía el mismo tipo de información pero en versión reducida. Además, el DAL contaba también con material videográfico.

Al finalizar la navegación, los participantes rellenaban un cuestionario relacionado con la experiencia en el que valoraban el proceso de interacción con una aplicación de publicidad interactiva para televisión. También se pidió a los sujetos que valoraran la posibilidad de solicitar uno u otro incentivo (según condición experimental) a través de una aplicación como la navegada. Los constructos analizados fueron valorados en escalas de Likert de cinco puntos, en las que los adjetivos positivos se situaban a la izquierda de la escala (=1) y sus contrapartidas negativas, a la derecha (=5).

\section{Resultados}

\subsection{Usabilidad de la aplicación}

De los 111 participantes, 104 decidieron navegar por la aplicación y 7 no lo hicieron. 69 participantes utilizaron el mecanismo de respuesta provisto en la aplicación.

Los usuarios que decidieron navegar por la aplicación $(\mathrm{n}=104)$ valoraron, de mediana, más bien agradable $(\mathrm{Me}=2)$, más bien cómodo $(\mathrm{Me}=2)$, más bien útil $(\mathrm{Me}=2)$ y sencillo $(\mathrm{Me}=1)$ el hecho de interactuar con una aplicación de publicidad interactiva en televisión. El gráfico siguiente muestra las medias globales obtenidas para cada variable en la pregunta "interactuar con una aplicación de publicidad interactiva en televisión me parece...". 


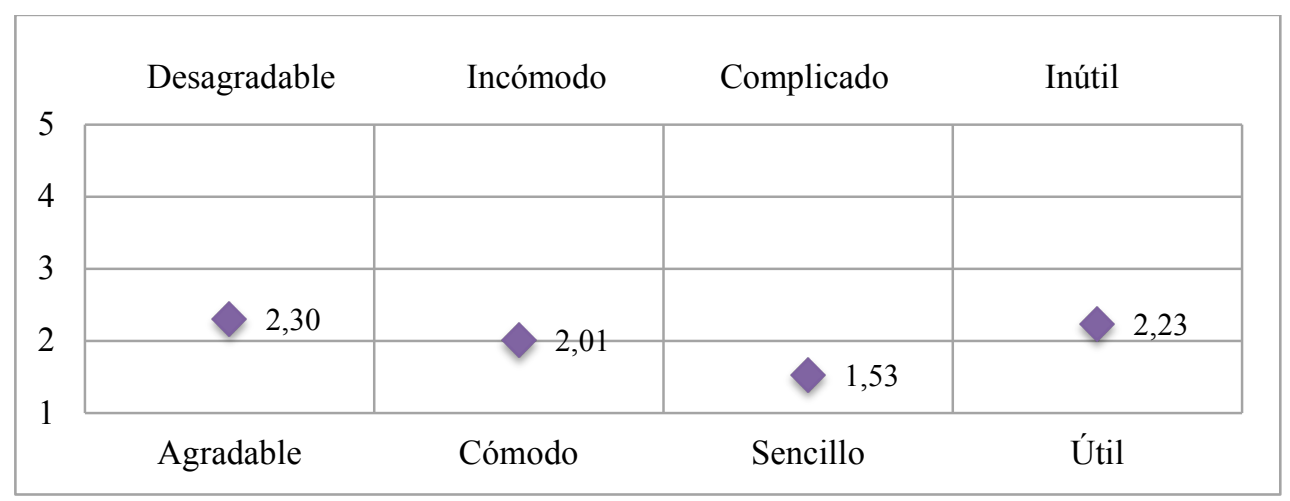

Gráfico 1. Usabilidad de la aplicación (medias globales)

En una comparación por tipo de aplicación (DAL, $n=52$; Mini-DAL, $n=52$ ), no se aprecian diferencias notables entre grupos. Las medianas en ambas aplicaciones se mantienen en los mismos valores expuestos en los resultados globales. Es decir, agrado, comodidad y utilidad tanto en DAL como en Mini-DAL se sitúan en Me=2 y sencillez en $\mathrm{Me}=1$. El gráfico 2 muestra las medias obtenidas en la cuestión "interactuar con una aplicación de publicidad interactiva en televisión me parece..." según aplicación navegada. Se realizó el test U de Mann-Whitney para comparar ambas aplicaciones. No se hallaron diferencias significativas en ninguna de las variables.

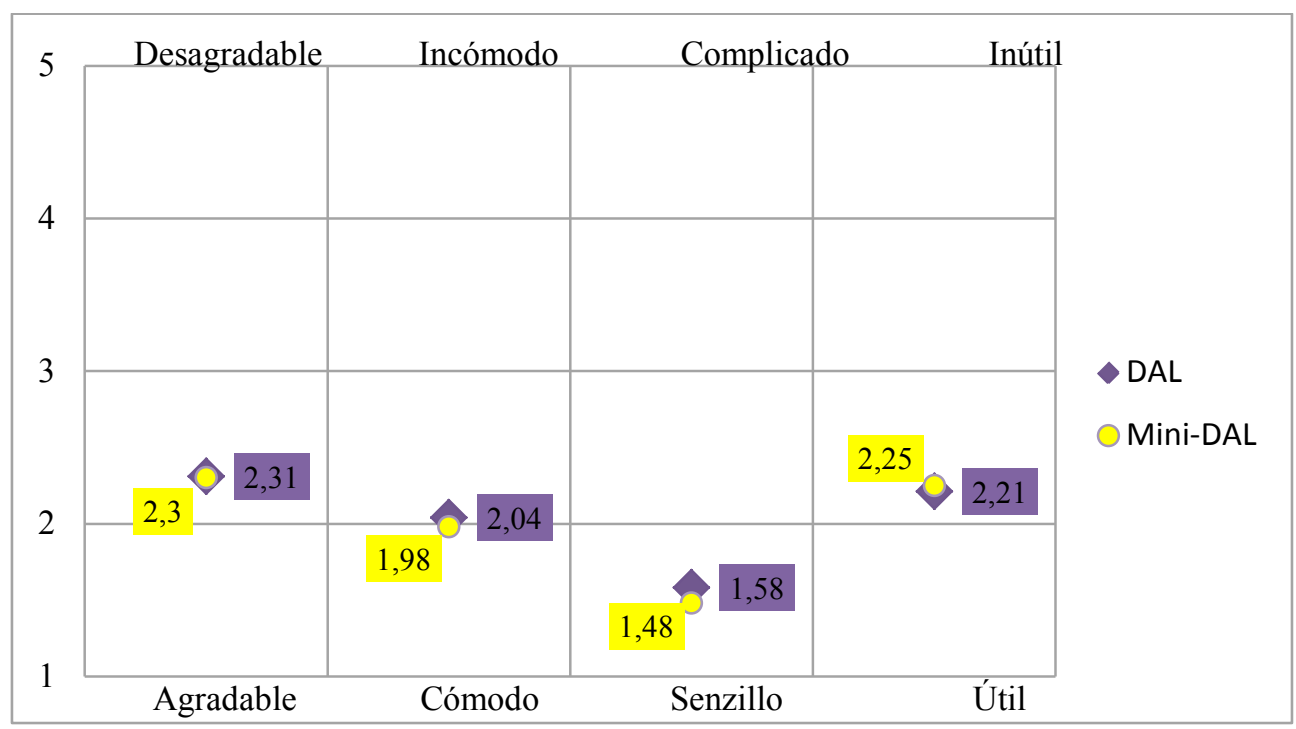

Gráfico 2. Usabilidad de la aplicación según aplicación navegada (medias) 


\subsection{El efecto del incentivo: muestra gratuita vs más información del producto}

Los participantes del estudio valoraron la posibilidad de solicitar una muestra gratuita o bien la posibilidad de solicitar más información sobre el producto a través del mecanismo de respuesta incorporado en la aplicación interactiva (según condición asignada). El cuestionario pedía a los participantes que valoraran de 1 a 5 cómo de deseable/indeseable, interesante/indiferente, beneficiosa/perjudicial, respetuosa/intrusiva, atractiva/repulsiva, útil/inútil, buena/mala, fiablelengañosa y de buen gusto/de mal gusto percibían esta posibilidad.

Los participantes a los que se ofreció la posibilidad de solicitar más información valoraron esta posibilidad como más bien deseable $(\mathrm{Me}=2)$, más bien interesante $(\mathrm{Me}=2)$, más bien beneficiosa $(\mathrm{Me}=2)$, más bien respetuosa $(\mathrm{Me}=2)$, más bien útil $(\mathrm{Me}=2)$, más bien buena $(\mathrm{Me}=2)$, ni fiable, ni engañosa $(\mathrm{Me}=3)$ y más bien de buen gusto $(\mathrm{Me}=2)$.

Aquellos usuarios a los que se ofreció la posibilidad de solicitar una muestra gratuita a través del mecanismo de respuesta valoraron como más bien deseable $(\mathrm{Me}=2)$, más bien interesante $(\mathrm{Me}=2)$, más bien beneficiosa $(\mathrm{Me}=2)$, ni respetuosa, ni intrusiva $(\mathrm{Me}=3)$, más bien útil $(\mathrm{Me}=2)$, más bien buena $(\mathrm{Me}=2)$, más bien engañosa $(\mathrm{Me}=4)$ y más bien de buen gusto $(\mathrm{Me}=2)$ esta posibilidad.

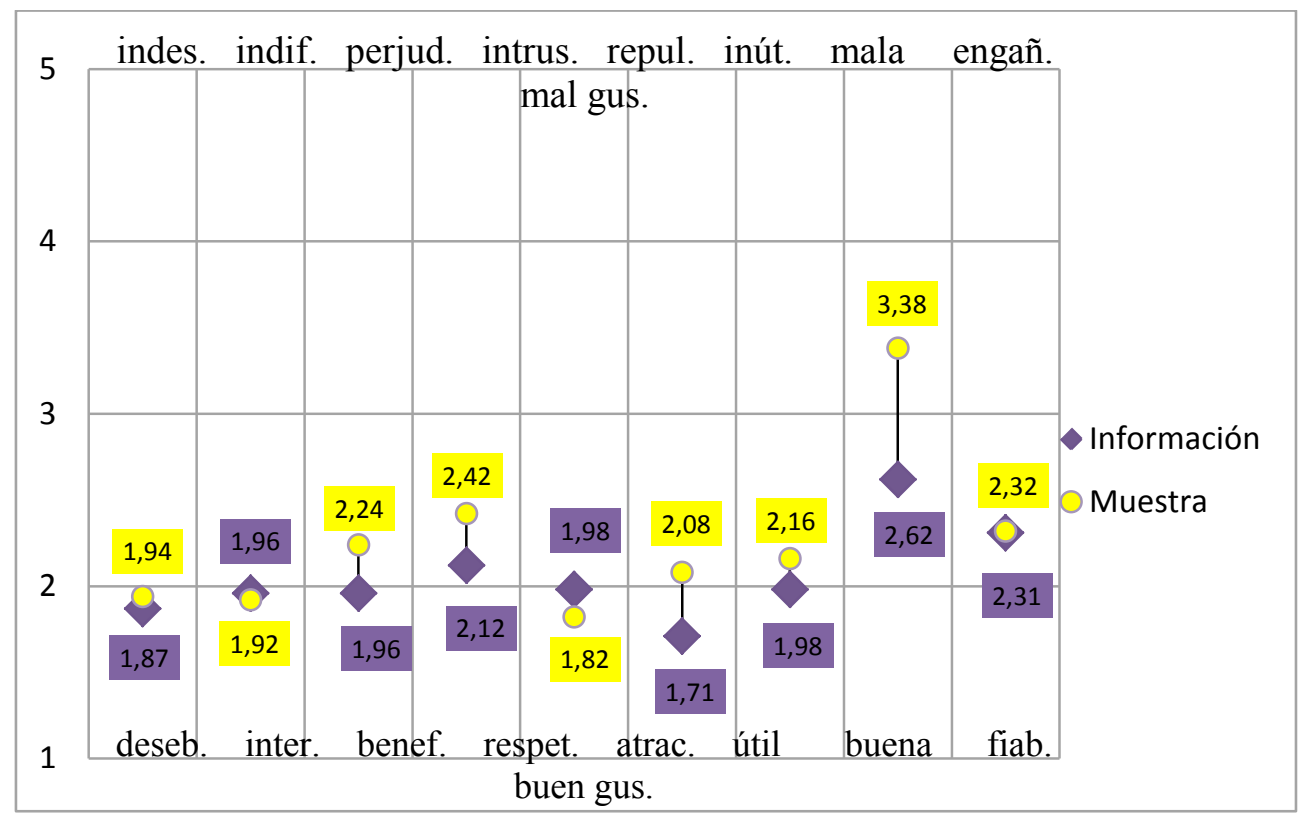

Gráfico 3. Solicitud de incentivo a través de la aplicación: más información vs muestra gratuita (medias) 
Como se puede observar en el gráfico la diferencia más amplia entre una y otra condición se encuentra en la variable fiabilidad. La variable utilidad, seguida de las variables intrusividad y beneficio muestran también una margen amplio de diferencia cuando se usa la media como valor de referencia. En este sentido, se efectuó la prueba estadística U- Mann Whitney para localizar diferencias significativas entre grupos. Se hallaron diferencias significativas en dos de las variables: fiabilidad y utilidad. Se percibe como más fiable y más útil la posibilidad de pedir más información sobre el producto a través del mecanismo de respuesta en comparación a pedir una muestra gratuita (ver cuadro 1).

\begin{tabular}{l|c|c|c|c}
\hline \multirow{2}{*}{ Variable } & \multicolumn{2}{|c|}{ Incentivo } & \multicolumn{2}{c}{ U- Mann Whitney } \\
\cline { 2 - 5 } & $\begin{array}{c}\text { Información } \\
\mathrm{n}=52 \\
\mathrm{M}(\mathrm{DT})\end{array}$ & $\begin{array}{c}\text { Muestra } \\
\mathrm{n}=52 \\
\mathrm{M}(\mathrm{DT})\end{array}$ & $\mathrm{U}$ & $\boldsymbol{p}$ (Sig.Asim.) \\
\hline $\begin{array}{l}\text { La posibilidad de solicitar una mues- } \\
\text { tra gratuita/ más información a través } \\
\text { de una aplicación de publicidad inter- } \\
\text { activa me parece útil(=1) - inútil(=5) }\end{array}$ & $1.71(.750)$ & $2.08(.877)$ & 1002.500 & .034 \\
\hline $\begin{array}{l}\text { La posibilidad de solicitar una mues- } \\
\text { tra gratuita/ más información a través } \\
\text { de una aplicación de publicidad inter- } \\
\begin{array}{l}\text { activa me parece fiable(=1) - engaño- } \\
\text { sa (=5) }\end{array}\end{array}$ & $2.62(.973)$ & $3.38(1.008)$ & 755.500 & .000 \\
\hline
\end{tabular}

Cuadro 1

\section{Discusión. Posibilidades para la publicidad en la televisión interactiva}

Los resultados del estudio muestran que la experiencia de interactuar con una aplicación de publicidad interactiva en televisión es en general positiva en todos los aspectos analizados (agrado, comodidad, sencillez y utilidad) y por lo tanto su implantación en el mercado podría recibir una buena acogida.

Los formatos interactivos pueden ser beneficiosos tanto para los telespectadores como para los anunciantes. Por ejemplo, estos formatos suponen una mejora en cuanto a las posibilidades de medir el impacto de las campañas y una mayor facilidad para recoger datos de los usuarios ya que resulta posible conocer el número de veces que los usuarios acceden a las aplicaciones y la duración del consumo (IAB, 2010). Además, facilitan el intercambio de información entre usuario y anunciante y potencian el branding, familiarizando el usuario con la marca y ofreciéndole 
servicios de valor añadido. También suponen un modelo publicitario más personalizado, focalizado y eficaz.

Sin embargo, es importante que antes de implementar este tipo de publicidad en nuestro mercado se repiensen los formatos existentes y se efectúen las innovaciones necesarias sobre éstos a fin que supongan un avance verdadero dentro de la publicidad, tanto en relación al propio medio televisivo como en relación a otros medios. En este sentido, las reflexiones que siguen podrían hacerse extensibles también al resto de aplicaciones interactivas para televisión.

La fase inicial de la investigación presentada, que consistió en la recogida de datos para elaborar una tipología de los formatos publicitarios existentes, detectó que los formatos que actualmente podemos encontrar en el mercado televisivo son en general muy simples. La navegación por estas aplicaciones aunque es ciertamente sencilla e intuitiva según se desprende del estudio efectuado, puede resultar tediosa y lenta si la comparamos con la publicidad de otros medios interactivos. Pensemos por ejemplo en rellenar un cuestionario con el mando a distancia o en desplazarnos por la aplicación con las flechas de este dispositivo en comparación a navegar por una página web en Internet. Además, los productos existentes en este sentido son por lo general visualmente menos atractivos y menos desarrollados que los que encontramos en medios más interactivos.

Por este motivo, el primer reto de los desarrolladores consiste en repensar la publicidad interactiva en la televisión. La televisión es un medio muy poderoso y la convergencia con la interactividad abre muchas puertas a nuevas formas de visionado e interacción con ella. Además, estudios como el presentado demuestran el interés de los telespectadores hacia estos formatos y su potencial en el mercado de la publicidad.

No obstante, no debemos olvidar que medios como móviles e Internet se encuentran mucho más avanzados en cuanto a lo que la interactividad representa, dada su naturaleza ya interactiva. Estos medios ofrecen a los usuarios formas de interacción mucho más complejas que las que puede ofrecer la televisión. Ante ello, el sector televisivo debe ser muy consciente de los puntos fuertes y débiles que tiene el medio en relación a otros medios ya de por sí interactivos y centrar sus esfuerzos en desarrollar productos en los que la interactividad sirva para potenciar las características diferenciales del medio. A su vez, no debe perderse de vista el ideal de la convergencia mediática como una realidad muy cercana. Así pues, los productos ideados deben aprovechar también las ventajas que ello supone.

En definitiva, el trabajo de los desarrolladores debe partir pues de esta doble perspectiva: trabajar en la potenciación de los rasgos sobresalientes del medio a través de la interactividad y secundar la convergencia mediática para incorporar aquello que otros medios pueden lograr mejor dada su naturaleza interactiva.

En este sentido, se proponen una serie de productos publicitarios interactivos con posibilidades de desarrollo dentro del nuevo panorama de la televisión interactiva, que secundan los criterios aquí expuestos. En primer lugar, entre los nuevos 
productos publicitarios que mejor pueden aprovechar las características audiovisuales del medio televisivo, están los formatos que potencian la publicidad audiovisual en forma de anuncios extendidos o de productos de advertainment. Los formatos que combinan publicidad y entretenimiento presentan un gran potencial como publicidad bajo demanda (on-demand advertising) en el medio televisivo.

Dado el poder persuasivo de la televisión, también debería desarrollarse una conexión más directa e inmediata entre la publicidad y la posibilidad de adquirir el producto o servicio anunciado a través de una aplicación de $T$-commerce asociada. No solamente a través de spots interactivos o de aplicaciones localizadas en los walled garden sino también de product placement interactivo, en el que por ejemplo fuera posible consultar la marca del pantalón que lleva la protagonista de una serie de ficción o de la lámpara que aparece en el comedor y comprarlos a través del televisor al momento (Swann, 2000).

También estarían en consonancia con lo expuesto todas aquellas formas publicitarias que busquen la cross-medialidad y aprovechen los puntos más fuertes de cada medio involucrado en la campaña.

Además, no se debe olvidar que, de hecho, el consumo televisivo ya no resulta exclusivo del televisor, sino que puede consumirse desde el ordenador, el móvil, los tablet $P C$, etc. Se trata en todos los casos de medios y soportes mucho más interactivos que la televisión tradicional y por lo tanto se pueden aprovechar las características de éstos para mejorar las aplicaciones existentes.

Por otra parte, el estudio reveló diferencias significativas entre la posibilidad de solicitar una muestra gratuita del producto o bien más información a través del mecanismo de respuesta contenido en la aplicación. En el caso concreto del estudio realizado ofrecer una muestra gratuita perjudicó significativamente la percepción de utilidad y fiabilidad. Este resultado indica que el tipo de incentivo ofrecido a través de estas aplicaciones es un elemento de importancia dado que podría afectar notablemente tanto la experiencia de navegación como la actitud hacia las aplicaciones de este tipo o incluso hacia la marca. En este sentido, sería conveniente que futuros estudios siguieran indagando en esta dirección, tanto en otro tipo de productos como en otros formatos publicitarios interactivos.

En resumen, la televisión interactiva abre muchas puertas a la publicidad. Estudios como el presentado demuestran que los usuarios podrían estar interesados en este tipo de productos publicitarios. Sin embargo, los formatos desarrollados hasta el momento no sólo resultan escasos en nuestro mercado y en el mercado televisivo en general sino que quizás no están suficientemente desarrollados o no son los más apropiados para triunfar en el medio televisivo dada la competencia que medios como Internet o los móviles suponen para la televisión interactiva. Por ello, tanto los desarrolladores como los académicos tienen en estos momentos más que nunca la misión de repensar cómo debe ser la publicidad en el nuevo entorno mediático con el objetivo de aprovechar de la mejor forma las nuevas oportunidades que le ofrece la televisión interactiva. 


\section{Referencias bibliográficas}

AYMERICH FRANCH, L. (2007): Nous formats publicitaris en televisió interactiva. Trabajo de investigación. Dir. Emili Prado y Matilde Delgado. Universitat Autònoma de Barcelona.

AYMERICH FRANCH, L. (2008):«Nous formats de publicitat interactiva en televisió. Una proposta per a la seva anàlisi i classificació». Quaderns del CAC, 30, 103-112.

AYMERICH FRANCH, L. (2010): Efecte de la complexitat de l'aplicació i del tipusd'incentiu sobre la motivació en publicitat interactiva per a televisió. Tesis doctoral. Dir. E. Prado y M. Delgado. Universidad Autónoma de Barcelona.

BAIRD, B. (2001): «Incentives». TM (Julio), 14.

Bellman, S., SchwedA, A. Y VARAN, D. (2009): "A Comparison of Three Interactive Television Ad Formats». Journal of Interactive Advertising,10(1), 14-34.

CHANNEL 4, CHANNEL 4 en línea. Interactive TV Ads. http://www.channel4.com/microsites/I/interactive tv sales. Web visitada el 4/2/2011.

IAB (2010):«Platform Status Report: An Interactve Television Advertising Overview. Interactive Advertising Bureau». http://www.iab.net. Web visitada el 17/2/2011.

SKY MEDIA IRELAND en línea. Sky Media. Interactive Advertising, http://www.skymedia.ie. Web visitada el 15/2/2011.

SKY Media United KINGDOM en línea. Sky Media. Advertising, http://www.skymedia.co.uk. Web visitada el 15/2/2011.

THINkBox (2011), Thinkbox en línea. http://www.thinkbox.tv.Web visitada el 18/2/2011.

READING, N., BELLMAN, S., VARAN, D. Y WINZAR, H. (2006): «Effectiveness of Telescopic Advertisements Delivered via Personal Video Recorders», Journal of Advertising Research, 46(2), 217-227.

SWANN, P. TV dot com: the future of interactive television. New York: TV Books, 2000.

TRUONG, Y., MCCOLL, R. Y KITCHEN, P. (2010):«Practitioners’ perceptions of advertising strategies for digital media», International Journal of Advertising, 29(5), 709-725.

Recibido: 11 de enero de 2012

Aceptado: 8 de noviembre de 2012 